\title{
Technical Note: A comparison of two empirical approaches to estimate in-stream net nutrient uptake
}

\author{
D. von Schiller ${ }^{1}$, S. Bernal ${ }^{2}$, and E. Martí ${ }^{2}$ \\ ${ }^{1}$ Leibniz-Institute of Freshwater Ecology and Inland Fisheries, Berlin, Germany \\ ${ }^{2}$ Biogeodynamics and Biodiversity Group, Centre d'Estudis Avançats de Blanes, CSIC, Blanes, Spain
}

Received: 20 September 2010 - Published in Biogeosciences Discuss.: 15 October 2010

Revised: 26 March 2011 - Accepted: 28 March 2011 - Published: 8 April 2011

\begin{abstract}
To establish the relevance of in-stream processes on nutrient export at catchment scale it is important to accurately estimate whole-reach net nutrient uptake rates that consider both uptake and release processes. Two empirical approaches have been used in the literature to estimate these rates: (a) the mass balance approach, which considers changes in ambient nutrient loads corrected by groundwater inputs between two stream locations separated by a certain distance, and (b) the spiralling approach, which is based on the patterns of longitudinal variation in ambient nutrient concentrations along a reach following the nutrient spiralling concept. In this study, we compared the estimates of in-stream net nutrient uptake rates of nitrate $\left(\mathrm{NO}_{3}\right)$ and ammonium $\left(\mathrm{NH}_{4}\right)$ and the associated uncertainty obtained with these two approaches at different ambient conditions using a data set of monthly samplings in two contrasting stream reaches during two hydrological years. Overall, the rates calculated with the mass balance approach tended to be higher than those calculated with the spiralling approach only at high ambient nitrogen $(\mathrm{N})$ concentrations. Uncertainty associated with these estimates also differed between both approaches, especially for $\mathrm{NH}_{4}$ due to the general lack of significant longitudinal patterns in concentration. The advantages and disadvantages of each of the approaches are discussed.
\end{abstract}

\section{Introduction}

Understanding the relevance of in-stream uptake on nutrient loads has become an important question over the past decades due to the need to establish reliable nutrient budgets

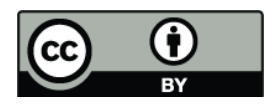

Correspondence to: D. von Schiller (danielvonschiller@igb-berlin.de) at catchment scale and to evaluate the impact of downstream nutrient export on coastal ecosystems (Behrendt and Opitz, 2000; Alexander et al., 2000; Wollheim et al., 2008). Several studies have shown that in-stream processes can have a significant influence on nutrient downstream transport, especially in headwater or relatively small-size streams (Alexander et al., 2000; Peterson et al., 2001; Bernhardt et al., 2003; Ensign and Doyle, 2006; Mulholland et al., 2008). Noteworthy, results from most of these studies are derived from estimates of gross nutrient uptake, which may overestimate the net influence of streams on nutrient downstream export because they do not consider processes associated to release of nutrients from biota to water column. Release processes (e.g. mineralization, nitrification, desorption), however, can be relevant in streams, and may counterbalance to some extent nutrient uptake processes (e.g. assimilation, denitrification, and adsorption) or even result in a net downstream release of nutrients. For instance, Brookshire et al. (2009) found no significant longitudinal patterns in ambient concentration (i.e. net uptake rates $\sim 0$ ) in about $80 \%$ of a selection of stream reaches from several biomes, and concluded that in-stream processes may be commonly irrelevant for watershed nutrient balances because in-stream nutrient uptake is rapidly balanced by nutrient release. Nevertheless, Brookshire et al. (2009) also suggested that streams could act as net sinks of nutrients (i.e. positive net uptake rates) under certain environmental conditions that favour denitrification or net biomass growth. Taking all this into consideration it becomes clear that, besides of characterizing stream ecosystems in terms of gross nutrient uptake rates, it is also important to estimate net nutrient uptake rates that provide more accurate information on actual nutrient export from a given stream reach and the relevance of in-stream processes at catchment scale.

In-stream net uptake rates integrate both uptake and release processes occurring along a reach, and can be positive

Published by Copernicus Publications on behalf of the European Geosciences Union. 
(uptake $>$ release), negative (uptake $<$ release) or nil (uptake $\sim$ release). These rates have been commonly estimated using a mass balance approach considering changes in nutrient loads (i.e. nutrient inputs minus outputs) between two stream locations separated by a certain distance (Meyer and Likens, 1979; Bernhardt et al., 2003; Roberts and Mulholland, 2007; Niyogi et al., 2010). In this approach, values of nutrient fluxes from groundwater to the stream are needed to accurately estimate the net mass balance only associated with uptake and release processes (i.e. in-stream net uptake rates). When groundwater nutrient concentrations are not available, a sensitivity analysis can be done using a range of potential values to examine the relevance of this nutrient source on estimated net nutrient uptake rates (Roberts and Mulholland, 2007).

Alternatively, in-stream net uptake rates can be estimated from patterns of longitudinal variation in ambient nutrient concentrations along a reach following the nutrient spiralling concept (Martí et al., 1997, 2004). Rather than assuming a linear trend of stream nutrient concentration between two locations, net uptake rates obtained with the spiralling approach are derived from the fit of ambient nutrient concentrations along the reach to an exponential equation (i.e. firstorder reaction model). This approach integrates all the uptake and release processes occurring along the stream reach and it works well regardless of nutrient groundwater inputs when they are negligible or when concentrations in groundwater and in surface water are similar. The uncertainty associated to processes occurring along the stream reach and to groundwater inputs can be estimated based on the confidence intervals of the fit to the exponential equation, yet, as for the mass balance approach, this procedure constitutes just a proxy to actual measurement uncertainty (Hanafi et al., 2007).

The aim of this study was to compare the estimates of instream net $\mathrm{N}$ uptake rates and the associated uncertainty obtained from the mass balance and the spiralling approaches aforementioned. To do so we took advantage of a data set from monthly samplings along a longitudinal transect in two contrasting stream reaches during two hydrological years, which allowed us to calculate net uptake rates of $\mathrm{NO}_{3}$ and $\mathrm{NH}_{4}$ with both methods under distinct hydrological and environmental conditions. The advantages and disadvantages of each method are discussed in view of the results from this comparison and the uncertainties associated with each method.

\section{Methods}

Data for this study were collected in two forested headwater streams located in Catalonia (NE Spain): Santa Fe del Montseny and Fuirosos. The two streams have contrasted hydrological regimes and dissolved inorganic N (DIN) concentrations (von Schiller et al., 2008). Santa Fe has per- manent flow year round, whereas Fuirosos has intermittent flow regime with summer no flow periods of variable duration among years. During the study period, DIN was dominated by $\mathrm{NO}_{3}$ in both streams, but the concentration was higher and expanded a wider range of values in Fuirosos (mean $\pm \mathrm{SD}=368 \pm 397 \mu \mathrm{g} \mathrm{N} 1^{-1}$, range $=35$ to $\left.1468 \mu \mathrm{g} \mathrm{N}^{-1}, n=20\right)$ than in Santa Fe $\left(125 \pm 83 \mu \mathrm{g} \mathrm{N} 1^{-1}\right.$, range $=12$ to $\left.321 \mu \mathrm{g} \mathrm{N}^{-1}, n=25\right)$. The concentration of $\mathrm{NH}_{4}$ was low (i.e. mean $<15 \mu \mathrm{g} \mathrm{N}^{-1}$ ) and showed no clear temporal pattern in both streams. More detailed information on the biogeochemical properties of these streams can be found in Bernal et al. (2005) and von Schiller et al. (2008).

Representative reaches of $140 \mathrm{~m}$ in Santa Fe and $80 \mathrm{~m}$ in Fuirosos were selected. We collected water samples for ambient concentrations of $\mathrm{NO}_{3}$ and $\mathrm{NH}_{4}$ and measured conductivity at eight locations along each reach. Discharge was estimated based on a mass balance approach by conducting short-term constant rate additions of a hydrological tracer (i.e. $\mathrm{NaCl}$ ) and using the time-curve conductivity data recorded at the bottom of the reach (Gordon et al., 2004). This method also allowed estimating variation of discharge along the reach due to groundwater inputs. Wetted width was recorded at each sampling location and averaged to provide a value for the entire reach. Field samplings were conducted monthly from September 2004 until August 2006, except in Fuirosos during no flow conditions. A total of 25 and 20 longitudinal samplings were done in Santa Fe and Fuirosos, respectively. Water samples were analyzed for $\mathrm{NO}_{3}$ and $\mathrm{NH}_{4}$ concentrations following standard colorimetric methods (von Schiller et al., 2008).

We calculated net uptake rates $\left(U\right.$, in $\left.\mu \mathrm{g} \mathrm{N} \mathrm{m}^{-2} \mathrm{~s}^{-1}\right)$ of each DIN form $\left(\mathrm{NO}_{3}\right.$ and $\left.\mathrm{NH}_{4}\right)$ for each sampling date using two alternative approaches: the mass balance approach and the spiralling approach.

The net uptake rates with the mass balance approach (hereafter referred to as $U_{\mathrm{MB}}$ ) were calculated using ambient $\mathrm{N}$ concentrations from the sampling locations at the top and the bottom of the reach. We took into consideration the groundwater $\mathrm{N}$ inputs to correct stream changes for this additional $\mathrm{N}$ source influencing the variation of $\mathrm{N}$ mass between the two sites following Roberts and Mulholland (2007). The $U_{\mathrm{MB}}$ was calculated using the equation:

$U_{\mathrm{MB}}=\left[\left(N_{\mathrm{top}} \cdot Q_{\mathrm{top}}\right)-\left(N_{\mathrm{bot}} \cdot Q_{\mathrm{bot}}\right)+\left(N_{\mathrm{gw}} \cdot Q_{\mathrm{gw}}\right)\right] /(x \cdot a)$

where $N$ (in $\mu \mathrm{g} \mathrm{N}^{-1}$ ) is the concentration of $\mathrm{NO}_{3}$ or $\mathrm{NH}_{4}$ measured at the top $\left(N_{\text {top }}\right)$ and bottom $\left(N_{\text {bot }}\right)$ of the reach and in the groundwater $\left(N_{\mathrm{gw}}\right), a$ (in $\mathrm{m}$ ) is the average wetted width, and $x$ (in $\mathrm{m}$ ) is the length of the reach between the top and the bottom sites. Discharge (in $1 \mathrm{~s}^{-1}$ ) of groundwater ( $Q_{\mathrm{gw}}$ ) was calculated as the difference between discharge at the top $\left(Q_{\text {top }}\right)$ and the bottom $\left(Q_{\text {bot }}\right)$ of the reach using data from the conservative tracer addition. $U_{\mathrm{MB}}$ was estimated assuming that $N_{\mathrm{gw}}$ was equal to average surface water concentration. Confidence intervals (CI, in $\mu \mathrm{g} \mathrm{N} \mathrm{m}^{-2} \mathrm{~s}^{-1}$ ) of $U_{\mathrm{MB}}$ were calculated based on the uncertainty associated with $N_{\mathrm{gw}}$ 
by assuming that it could range from 0.5 to 2 times the average surface water $\mathrm{N}$ concentration (Roberts and Mulholland, 2007). Subsurface N concentrations measured sporadically in the hyporheic zone of both streams tended to be within this range of values. In Santa Fe, the median [quartiles] subsurface/surface concentration ratio was $1.17[1.05,1.25]$ and $1.15[0.94,1.62]$ for $\mathrm{NO}_{3}(n=23)$ and $\mathrm{NH}_{4}(n=21)$, respectively. In Fuirosos, only $\mathrm{NO}_{3}$ was measured and was $1.08([0.54,1.89], n=22)$. The CI was calculated as the difference between the upper and the lower limit of $U_{\mathrm{MB}}$. We assumed that $U_{\mathrm{MB}}$ was not different from 0 when the upper limit was positive and the lower limit was negative.

The net uptake rates from the spiralling approach (hereafter referred to as $U_{\mathrm{SP}}$ ) were calculated using the longitudinal variation in ambient $\mathrm{N}$ concentration along the reach. Stream ambient concentrations were corrected by the longitudinal variation in ambient conductivity based on the method described by Martí et al. (2004). We used conductivity which correlates well with the concentration of chloride in the study streams (D. von Schiller, unpublished data); however, measuring directly the concentration of a conservative tracer (e.g. chloride, bromide) is recommended. This method is an adaptation of the method used to estimate nutrient spiralling metrics using short-term nutrient additions (Newbold et al., 1981; Webster and Valett, 2006). The underlying assumptions are: (a) changes in stream ambient conductivity only occur if groundwater inputs differ in conductivity with respect to surface water, and (b) groundwater inputs dilute or enrich surface water conductivity and $\mathrm{N}$ concentration at the same longitudinal rate if groundwater concentrations are different from those in surface water. Consequently, net uptake or release of $\mathrm{N}$ is considered to occur when the proportion of ambient $\mathrm{N}$ concentration over ambient conductivity increases or decreases significantly with distance downstream. From the longitudinal patterns in ambient concentrations, we estimated a net uptake coefficient per unit of reach length $\left(k_{w}\right.$, in $\mathrm{m}^{-1}$ ) by solving the equation:

$N_{x}=N_{\mathrm{top}} \cdot\left(C_{x} / C_{\mathrm{top}}\right) \cdot e^{k_{w} x}$

where $N$ (in $\mu \mathrm{g} \mathrm{N}^{-1}$ ) is the ambient concentration of $\mathrm{NO}_{3}$ or $\mathrm{NH}_{4}$, and $C$ (in $\mu \mathrm{S} \mathrm{cm}^{-1}$ ) is the ambient conductivity at the top of the reach and at the downstream sites located $x \mathrm{~m}$ from the top of the reach. $U_{\mathrm{SP}}$ was then calculated using the following equation:

$U_{\mathrm{SP}}=\left(Q \cdot N_{\mathrm{avg}} \cdot k_{w}\right) / a$

where $N_{\text {avg }}$ (in $\mu \mathrm{g} \mathrm{N}^{-1}$ ) is the average of the $\mathrm{N}$ ambient concentration measured at the eight locations along the reach and $Q$ (in $1 \mathrm{~s}^{-1}$ ) is average discharge along the reach. We estimated the CI of $U_{\mathrm{SP}}$ based on the $k_{w}$ range obtained using the $\pm 95 \%$ confidence interval of the regression between $\mathrm{N}$ concentration corrected by ambient conductivity (i.e. $\ln N_{x}$ ) and the downstream distance $(x)$ derived from Eq. (2). The value of $U_{\mathrm{SP}}$ was not statistically different from zero when the regression was not significant (i.e. $p>0.05$ ). The $\mathrm{CI}$ (in $\mu \mathrm{g} \mathrm{N} \mathrm{m}^{-2} \mathrm{~s}^{-1}$ ) for $U_{\mathrm{SP}}$ was estimated as the difference in the $U_{\mathrm{SP}}$ values between the upper and lower $95 \%$ confidence intervals. We assumed that $U_{\mathrm{SP}}$ was not different from 0 when the upper limit was positive and the lower limit was negative.

We used Wilcoxon paired tests and Spearman rank correlations to compare $U_{\mathrm{MB}}$ and $U_{\mathrm{SP}}$ estimates for $\mathrm{NO}_{3}$ and $\mathrm{NH}_{4}$. Non-parametric tests were chosen because data did not meet normality requirements even after data transformations. All statistical analyses where done with Statistica 7.0 (Statsoft, Tulsa, Oklahoma, USA).

\section{Results and discussion}

On many sampling dates, the concentrations of $\mathrm{NO}_{3}$ and $\mathrm{NH}_{4}$ showed a longitudinal decline or increase in both streams, suggesting non-equilibrium of in-stream processes (uptake $\neq$ release; Brookshire et al., 2009). The net uptake rates calculated using the mass balance and the spiralling approaches fell close to the 1:1 line for both DIN forms (Fig. 1). For $\mathrm{NO}_{3}$, however, $U_{\mathrm{MB}}$ (median [quartiles] $=0.11[-0.04$, $\left.0.25] \mu \mathrm{g} \mathrm{N} \mathrm{m}^{-2} \mathrm{~s}^{-1}, n=45\right)$ was two times higher than $U_{\mathrm{SP}}$ $\left(0.06[-0.04,0.23] \mu \mathrm{g} \mathrm{N} \mathrm{m}^{-2} \mathrm{~s}^{-1}, n=45\right)$ (Wilcoxon paired test, Signed-Rank $=239.5, d f=44, p<0.01)$. The discrepancy in the estimation of $U$ between the two approaches emerged under high ambient $\mathrm{NO}_{3}$ concentrations. We found that absolute differences between the $U$ for $\mathrm{NO}_{3}$ calculated with the two approaches augmented as stream $\mathrm{NO}_{3}$ concentration increased (Spearman Rho coefficient $=0.71, d f=44$, $p<0.01$ ) (Fig. 2a). In fact, there were no differences between $U_{\mathrm{MB}}$ and $U_{\mathrm{SP}}$ for those cases in which stream $\mathrm{NO}_{3}$ concentrations were $<\sim 300 \mu \mathrm{g} \mathrm{N}^{-1}$ (Wilcoxon paired test, Signed-Rank $=92, d f=34, p>0.05)$. Consistent with the findings for $\mathrm{NO}_{3}$ in which differences between the two approaches were small when stream $\mathrm{N}$ concentrations were low, the values for $\mathrm{NH}_{4}$ (in all cases ambient concentration $\left.<30 \mu \mathrm{g} \mathrm{N}^{-1}\right)$ of $U_{\mathrm{MB}}\left(0.03[-0.02,0.06] \mu \mathrm{g} \mathrm{N} \mathrm{m}^{-2} \mathrm{~s}^{-1}\right.$, $n=45)$ and $U_{\mathrm{SP}}\left(0.03[-0.01,0.08] \mu \mathrm{g} \mathrm{N} \mathrm{m} \mathrm{s}^{-2} \mathrm{~s}^{-1}, n=\right.$ 45) showed no differences (Wilcoxon paired test, SignedRank $=-60.5, d f=44, p>0.05)$ and did not exhibit any consistent pattern in relation to stream $\mathrm{NH}_{4}$ ambient concentrations (Fig. 2b).

The mass balance and the spiralling approaches differ in a basic methodological assumption. While the mass balance approach assumes that the concentration of $\mathrm{N}$ changes linearly between the sampling stations located at the top and bottom of the study reach, the spiralling approach presupposes an exponential change of concentration with distance downstream. Thus, assuming constant discharge along the reach (i.e. $Q_{\mathrm{gw}} \sim 0$ ), it can be derived from Eq. (1) that $U_{\mathrm{MB}}$ is directly dependent on the difference in $\mathrm{N}$ concentration between the two sites (i.e., $N_{\text {top }}-N_{\text {bot }}$ ). Following the same assumption, and considering the simplest case with only two stations along the stream reach (top and bottom), it can be 
A

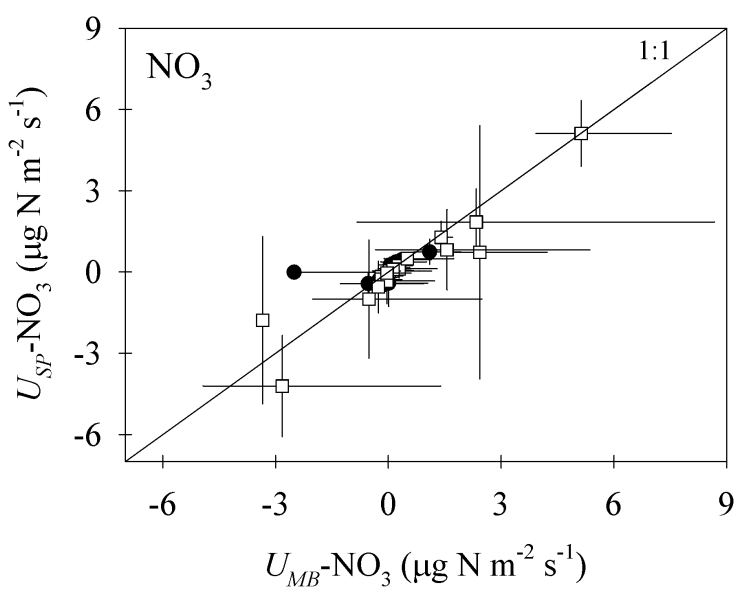

B

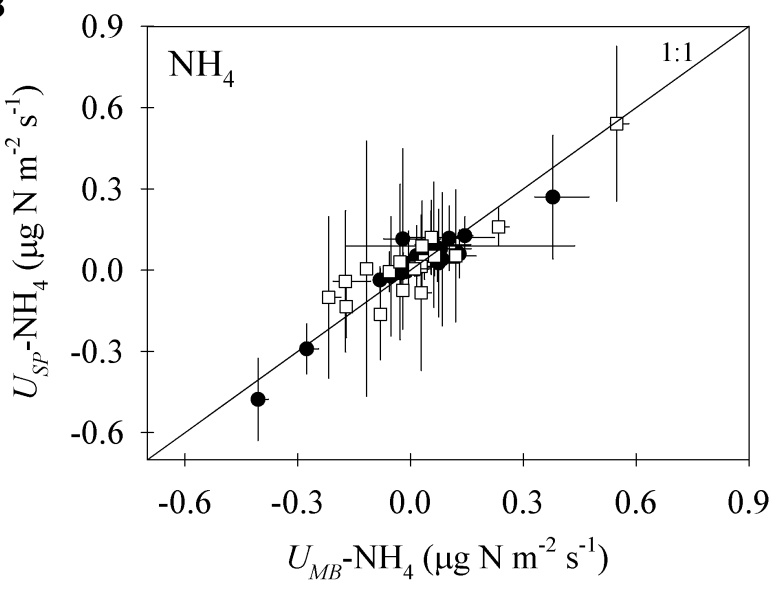

Fig. 1. Relationship between the net uptake rates estimated with the mass balance approach $\left(U_{\mathrm{MB}}\right)$ and the spiralling approach $\left(U_{\mathrm{SP}}\right)$ for (A) $\mathrm{NO}_{3}$ and (B) $\mathrm{NH}_{4}$. White squares and black circles correspond to values from Fuirosos $(n=20)$ and Santa Fe $(n=25)$ streams, respectively. Error bars are the confidence intervals estimated with the two approaches (see text for details). The 1:1 line is shown in each case.

derived from Eqs. (2) and (3) that $U_{\text {SP }}$ depends on the average $\mathrm{N}$ concentration as well as on the ratio in $\mathrm{N}$ concentration between the two stations (i.e. $N_{\text {avg }} \ln \left(N_{\text {top }} / N_{\text {bot }}\right)$; see interactive discussion for details of derivations). Based on Eqs. (1)(3), it is also worth considering that the distance between the two sampling stations (i.e. reach length) may influence the comparison of $U$ estimates between the two methods. We used a sensitivity analysis to examine how the difference between $U_{\mathrm{MB}}$ and $U_{\mathrm{SP}}$ changed as a function of: (a) the average stream water $\mathrm{N}$ concentration, (b) the reach length considered, and (c) the ratio in $\mathrm{N}$ concentration between the top and bottom stations (Fig. 3). Results from this analysis supported our empirical results, showing that the difference between both approaches increases linearly with increasing average $\mathrm{N}$ concentration (Fig. 3a). Moreover, results show that the difference between both approaches decreases as a power law when the reach length increases (Fig. 3b). Finally, results
A

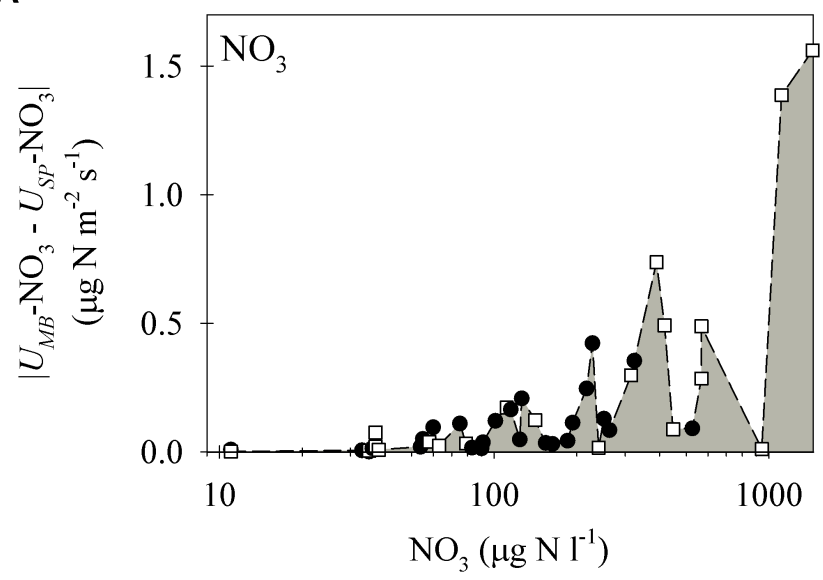

B

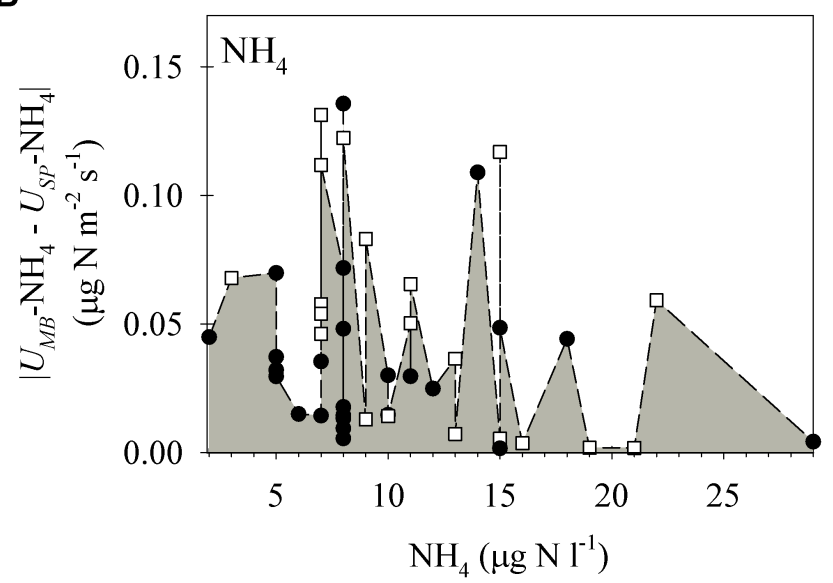

Fig. 2. Absolute differences between the net uptake rates estimated with the mass balance approach $\left(U_{\mathrm{MB}}\right)$ and the spiralling approach $\left(U_{\mathrm{SP}}\right)$ sorted as a function of average stream $\mathrm{N}$ concentration for (A) $\mathrm{NO}_{3}$ and (B) $\mathrm{NH}_{4}$. White squares and black circles correspond to values from Fuirosos $(n=20)$ and Santa Fe $(n=25)$ streams, respectively. Note logarithmic scale on the $\mathrm{x}$-axis of $(\mathbf{A})$.

from the sensibility analysis indicate that the $U_{\mathrm{MB}}-U_{\mathrm{SP}}$ difference is magnified as the $N_{\text {top }}: N_{\text {bot }}$ ratio increases.

Measurements of uncertainty differed between the mass balance and the spiralling approaches for both DIN forms (Fig. 4). For $\mathrm{NO}_{3}$, the confidence intervals calculated with the mass balance approach were larger than those estimated with the spiralling approach (Fig. 4a; Wilcoxon paired test, Signed-Rank $=249, d f=44, p<0.01)$. The sensitivity analysis indicated that $U_{\mathrm{MB}}$ could vary strongly depending on the $N_{\mathrm{gw}}$ scenario considered. The $U_{\mathrm{MB}}$ for $\mathrm{NO}_{3}$ decreased on average $3.8 \pm 9.7$ times when the $\mathrm{NO}_{3}$ concentration in groundwater was half that of surface water, and it increased $8.2 \pm 19.3$ times when the $\mathrm{NO}_{3}$ concentration in groundwater was doubled with respect to surface water. In contrast, the $U_{\mathrm{SP}}$ for $\mathrm{NO}_{3}$ varied only $2.7 \pm 1.5$ times due to the uncertainty associated with this approach. Despite of differences in the uncertainty associated with each approach, our 
A

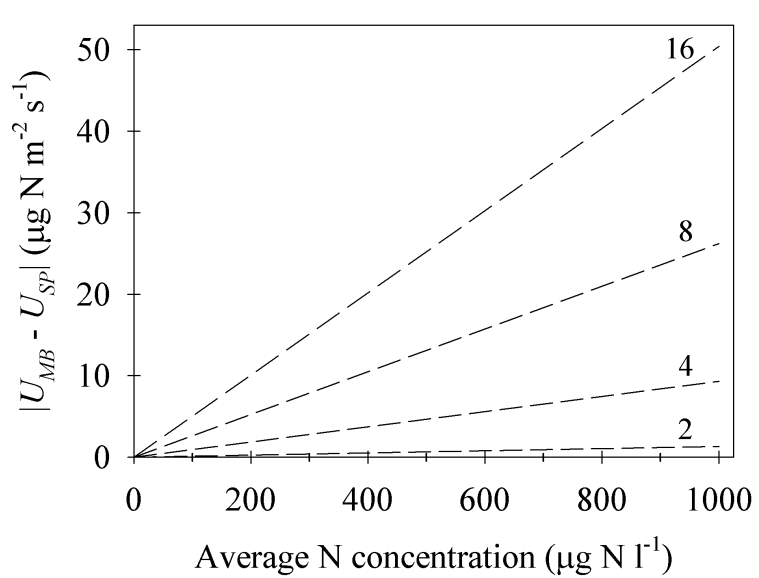

B

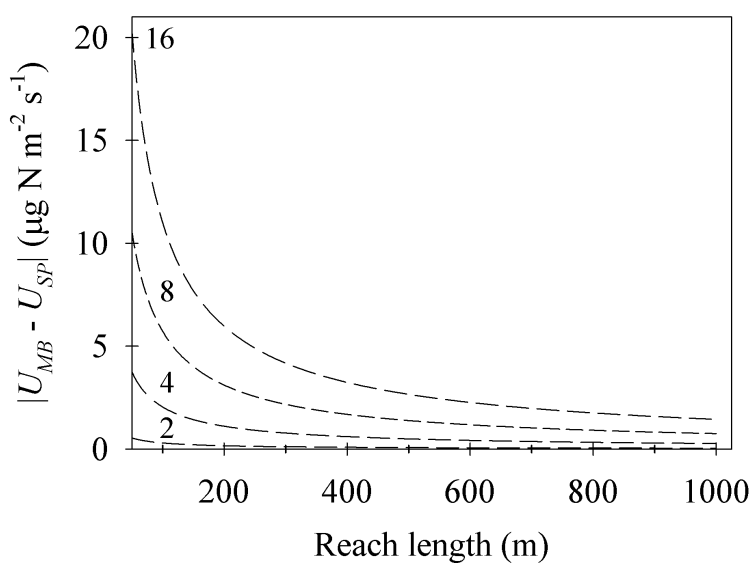

Fig. 3. Sensitivity analysis of the influence of (A) average stream water $\mathrm{N}$ concentration and $(\mathbf{B})$ reach length on the absolute difference between net uptake rates estimated with the mass balance approach $\left(U_{\mathrm{MB}}\right)$ and the spiralling approach $\left(U_{\mathrm{SP}}\right)$. Constant discharge $\left(101 \mathrm{~s}^{-1}\right)$ and wetted width $(2 \mathrm{~m})$ were considered between only two stream stations (top and bottom). In (A) reach length $=100 \mathrm{~m}$, and in $(\mathbf{B})$ average $\mathrm{N}$ concentration $=200 \mu \mathrm{g} \mathrm{Nl}^{-1}$. Numbers on each dashed line correspond to different proportions of stream $\mathrm{N}$ concentration between the top and bottom stations.

results indicated either net in-stream uptake $(U>0)$ or release $(U<0)$ of $\mathrm{NO}_{3}$ (i.e. non-equilibrium of net in-stream processes) in $40 \%$ and $49 \%$ of the cases for the mass balance and the spiralling approach, respectively. These percentages suggest that the relevance of in-stream processes on $\mathrm{NO}_{3}$ export can potentially be higher than previously reported for other streams (Brookshire et al., 2009).

Nonetheless, of the total cases with net uptake/release of $\mathrm{NO}_{3}$ estimated with the mass balance approach $\left(U_{\mathrm{MB}} \neq 0\right)$, $44 \%$ ( 8 out of 18 ) lead to net uptake/release $\left(U_{\mathrm{SP}}=0\right)$ when applying the spiralling approach. Thus, in these cases, the longitudinal change in ambient stream water $\mathrm{N}$ concentration from the top to the bottom stations showed an unclear and statistically non-significant longitudinal pattern. In turn, of the estimates with $U_{\mathrm{SP}} \neq 0$ for $\mathrm{NO}_{3}, 55 \%$ (12 out of 22)
A

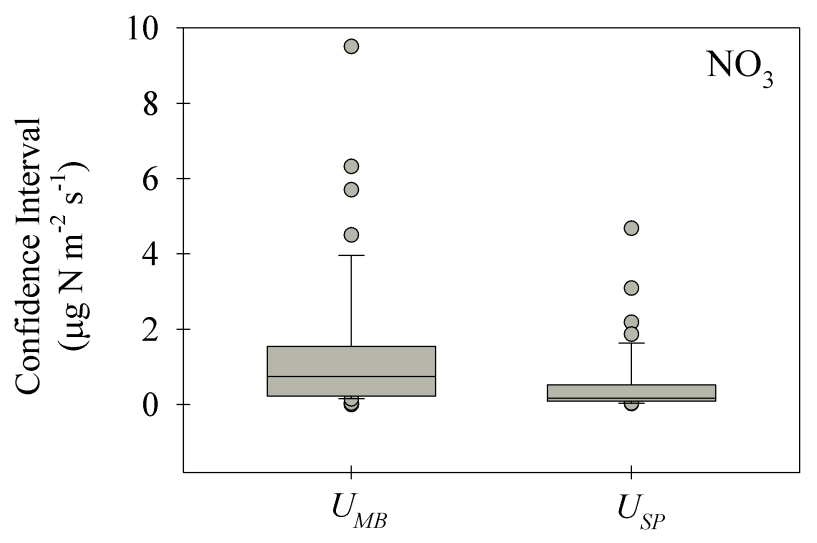

B

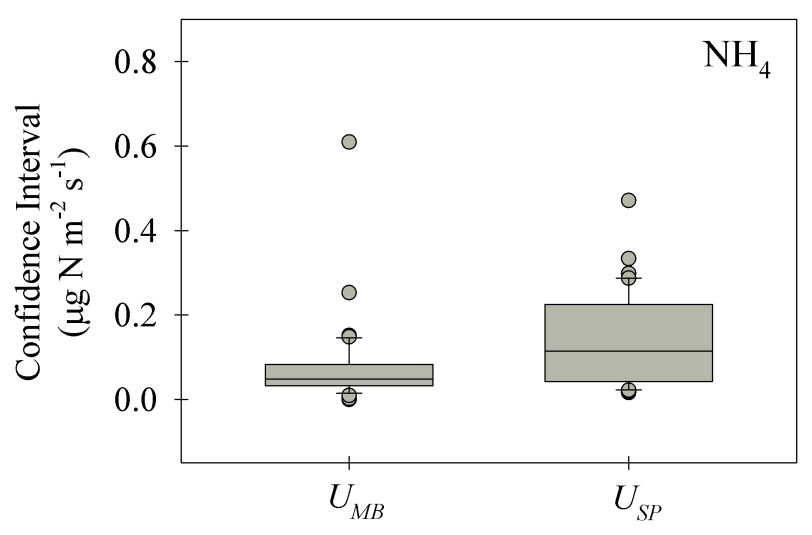

Fig. 4. Box plots summarizing the confidence intervals (CI) calculated for the net uptake rates using the mass balance approach $\left(U_{\mathrm{MB}}\right)$ and the spiraling approach $\left(U_{\mathrm{SP}}\right)$ for $(\mathbf{A}) \mathrm{NO}_{3}$ and (B) $\mathrm{NH}_{4}$. Data are from Santa $\mathrm{Fe}(n=25)$ and Fuirosos $(n=20)$ streams. The centre horizontal line in each plot is the median value. Fifty percent of the data points lie within each box. The whiskers above and below the box indicate the $90 \%$ and $10 \%$ percentiles. Circles are outliers. See text for details on the calculation of the CI for each approach.

lead to $U_{\mathrm{MB}}=0$ when applying the mass balance approach. In these cases, net changes in ambient stream $\mathrm{NO}_{3}$ concentration between the top and the bottom stations could potentially be explained solely (without in-stream uptake/release) by groundwater inputs with a concentration within the range considered here $(0.5-2$ times the mean surface water concentration). These results highlight the inherent uncertainties of both approaches, and show when values from the two approaches are comparable. Thus, applying both empirical approaches may help researchers to decide which method is most suitable for their particular case. In addition, if results from both methods are coincident, one might be more confident of the obtained estimates.

In contrast to $\mathrm{NO}_{3}$, the confidence intervals calculated for $\mathrm{NH}_{4}$ with the spiralling approach were higher than those 
obtained with the mass balance approach (Fig. 4b, Wilcoxon paired test, Signed-Rank $=-427, d f=44, p<0.01$ ). The uncertainty associated with groundwater inputs for $\mathrm{NH}_{4}$ was low compared to that associated with $\mathrm{NO}_{3}$ due to the relatively low $\mathrm{NH}_{4}$ concentration of these inputs. In relative terms, the $U_{\mathrm{MB}}$ for $\mathrm{NH}_{4}$ decreased on average $2.2 \pm 2.4$ times and increased $1.1 \pm 1.1$ times when groundwater inputs were half and 2-fold those in surface water, respectively. For the spiralling approach, $U_{\mathrm{SP}}$ varied on average $5.9 \pm 13.1$ times due to the uncertainty associated with this calculation. In contrast to $\mathrm{NO}_{3}$, the longitudinal pattern of ambient $\mathrm{NH}_{4}$ concentrations across all sampling stations was rarely statistically significant. The mass balance approach, based only on a top and a bottom stations, suggested non-equilibrium of in-stream processes (i.e. $U \neq 0$ ) for $76 \%$ of the studied cases. Contrastingly, according to the spiralling approach there was only net uptake or release of $\mathrm{NH}_{4}$ in $29 \%$ of the cases. Of the $U_{\mathrm{MB}} \neq 0$ estimates for $\mathrm{NH}_{4}, 68 \%$ (23 out of 34) coincided with $U_{\mathrm{SP}}=0$ estimates. In contrast, of the $U_{\mathrm{SP}} \neq 0$ estimates for $\mathrm{NH}_{4}$, only $15 \%$ ( 2 out of 13) coincided with $U_{\mathrm{MB}}=0$ estimates.

Overall, results from this study showed discrepancies in the estimates of in-stream net uptake rates of DIN forms between the mass balance and the spiralling approach, in particular under high $\left(>300 \mu \mathrm{g} \mathrm{N}^{-1}\right)$ ambient $\mathrm{N}$ concentrations. For lower ambient $\mathrm{N}$ concentrations, however, net uptake rates obtained with the two alternative approaches were similar. Roberts and Mulholland (2007) reported a small effect of groundwater inputs on $\mathrm{N}$ in-stream net uptake rates in the West Fork of Walker Branch (Tennessee, USA), where stream ambient DIN concentrations were low $\left(<100 \mu \mathrm{g} \mathrm{N}^{-1}\right)$. We showed, however, that groundwater inputs could strongly influence estimation of in-stream net uptake rates when stream ambient concentrations are high, such in the case of $\mathrm{NO}_{3}$ in our data set, or under large $N_{\text {top }}: N_{\text {bot }}$ ratios. When this is the case, riparian groundwater samples may be collected to constrain the range of uncertainty in $U$ associated with this nutrient source (Roberts and Mulholland, 2007). However, reliable riparian groundwater concentration measurements are difficult to obtain due to the high spatial variability (Lewis et al., 2006) and the potential difference between groundwater and the water found at the interface between the ground and surface water which really enters the stream (Brookshire et al., 2009). This limitation can be a disadvantage when using the mass balance approach under certain conditions, such as high lateral inflow or high stream nutrient concentrations. Conversely, for the alternative spiraling approach the influence of additional groundwater sources can only be relevant in cases when nutrient concentration in groundwater is highly different from that in the surface stream because estimates are based on changes in nutrient concentration rather than in nutrient mass.

The spiralling approach is based on a whole-reach integrative measure of a longitudinal concentration trend across several sampling points, contrasting with the net change in nutrient loads between only two sampling points considered by the mass balance approach. In addition, estimates of $U$ by the spiralling approach are based on a first-order reaction model, which is likely to be more representative for instream nutrient dynamics than the linear model used by the mass balance approach (Newbold et al., 1981; Webster and Valett, 2006). We showed that when longitudinal patterns are unclear, such as is often the case for $\mathrm{NH}_{4}$, the spiralling approach shows higher uncertainty and a higher proportion of estimates of $U=0$ (i.e. equilibrium of net in-stream processes) compared to the mass balance approach, which may tend to overestimate those cases in which there is net uptake or release. An important limitation of the spiralling approach is the assumption that changes in stream water conductivity along the reach respond to groundwater inputs and, more importantly, that the effect of groundwater inputs on $\mathrm{N}$ stream concentration is proportional to that of conductivity. The latter assumption may not consistently hold across streams. If groundwater data are not available along the reach, as it is often the case, this assumption is difficult to test, yet it seems reasonable to consider that changes in groundwater conductivity could be associated with changes in nutrient concentrations, especially in streams subjected to anthropogenic inputs. Under these conditions, the spiralling approach will provide an estimate of overall net nutrient change rates rather than of in-stream nutrient uptake. However, because $U_{\text {SP }}$ estimates are based on changes in nutrient concentration and not in mass, the influence of groundwater inputs on the longitudinal patterns of stream ambient nutrient concentration might be smaller when groundwater inflow is low relative to stream discharge and also when groundwater concentrations are similar to those in stream water.

A common limitation of both approaches is that they do not consider the potential effect of concurrent gain and loss of stream water on solute concentrations along the study stream (Covino and McGlynn, 2007; Payn et al., 2009). We observed net increases or constant discharge along the reach (i.e. $Q_{\mathrm{gw}} \geq 0$ ) in both streams on all sampling dates. The median [quartiles] percentage increase of discharge along the reach was 17.2 [9.4, 23.4] in Santa Fe and 8.8 [5.1, 12.9] in Fuirosos. However, we could not determine if there were concurrent gross gains or losses, which have been shown to occur over relatively short stream reaches (Payn et al., 2009). These gross gains and losses may change stream solute concentrations and fluxes, and consequently affect the estimation of net nutrient uptake using the methods compared in this study and other widely used methods (e.g. solute additions) for studying nutrient dynamics at the reach scale. Nonetheless, as discussed above, this issue is more likely to affect results from the mass balance approach than from the spiralling approach because bidirectional surface-subsurface flow exchange is expected to have a higher influence of nutrient mass than on nutrient concentration. 
Another limitation of the mass balance and the spiraling approaches is that they do not allow determining the mechanisms driving nutrient uptake. For instance, using these approaches we are not able to distinguish whether the removal of inorganic $\mathrm{N}$ is permanent (through denitrification), or temporary (through biotic assimilation and adsorption). Moreover, a stream may have no net effect on total nutrient export, yet it may have large net uptake of inorganic nutrients which are stored for some time and then exported as organic forms (Bernhardt et al., 2003).

Although the spiralling approach has been less commonly used in the literature, data sets of ambient nutrient concentration collected along stream longitudinal transects are often available from nutrient uptake studies using the nutrient addition methodology for which background nutrient concentrations are measured along the study reach (Webster and Valett, 2006; Ensign and Doyle, 2006). We encourage other researchers to profit from such data to obtain reliable in-stream net uptake rates and to compare the mass balance and the spiralling approaches across further systems. Furthermore, if data on both gross (e.g., from nutrient additions) and net nutrient uptake are available, rates of mineralization could potentially be inferred. This information is relevant to expand our knowledge on broad temporal and spatial patterns of net in-stream nutrient uptake rates, which could be based on different sources of existing data.

Acknowledgements. We thank M. Ribot, A. Argerich, P. Fonollà and S. Pla for field and laboratory assistance. We are also grateful to the direction of the Natural Parks of Montseny and Corredor-Montnegre (Diputació de Barcelona) for allowing access to the sampling sites. Thoughtful comments by W. Wollheim, B. Hall and M. Gooseff improved the quality of this manuscript. D. von Schiller was supported by a postdoctoral fellowship of the German Academic Exchange Service and "laCaixa" Foundation. S. Bernal was supported by a Juan de la Cierva postdoctoral fellowship (JC2008-1777) from the Spanish Ministry of Science and Innovation. Financial support for data collection was provided by the European Union through the EURO-LIMPACS project (ref: GOCE-CT-2003-505540, www.eurolimpacs.ucl.ac.uk) and by the Spanish Ministry of Science and Innovation through the GRACCIE project (ref: CSD2007-00067, Consolider Program).

Edited by: T. J. Battin

\section{References}

Alexander, R. B., Smith R. A., and Schwarz, G. E.: Effect of stream channel size on the delivery of nitrogen to the Gulf of Mexico, Nature, 403, 758-761, 2000.

Behrendt, H. and Opitz, D.: Retention of nutrients in river systems: dependence on specific runoff and hydraulic load, Hydrobiologia, 410, 111-122, 1999.

Bernal, S., Butturini, A., and Sabater, F.: Seasonal variations of dissolved nitrogen and DOC:DON ratios in an intermittent Mediterranean stream, Biogeochemistry, 75, 351-372, 2005.
Bernhardt, E. S., Likens, G. E., Buso, D. C., and Driscoll, C. T.: In-stream uptake dampens effects of major forest disturbance on watershed nitrogen export, P. Natl. Acad. Sci. USA, 100, 10304 10308, 2003.

Brookshire, E. N., Valett, H. M., and Gerber, S.: Maintenance of terrestrial nutrient loss signatures during in-stream transport, Ecology, 90, 293-299, 2009.

Covino, T. P. and McGlynn, B. L.: Stream gains and losses across a mountain-to-valley transition: Impacts on watershed hydrology and stream water chemistry, Water Resour. Res., 43, W10431, doi:10.1029/2006WR005544, 2007.

Ensign, S. H. and Doyle, M. V.: Nutrient spiraling in streams and river networks, J. Geophys. Res., 111, G04009, doi:10.1029/2005JG000114, 2006.

Gordon, N. D., McMahon, T. A., Finlayson, B. L., Gippel, C. J., and Nathan, R. J.: Stream hydrology: an introduction for ecologists, Wiley, West Sussex, UK, 2004.

Hanafi, S., Grace, M., Webb, J. A., and Hart, B.: Uncertainty in nutrient spiraling: sensitivity of spiraling indices to small errors in measured nutrient concentration, Ecosystems, 10, 477-487, 2007.

Lewis D. B., Schade, J. D., Huth, A. K., and Grimm, N. B.: The spatial structure of variability in a semi-arid, fluvial ecosystem, Ecosystems, 9, 386-397, 2006.

Martí, E., Grimm, N. B., and Fisher, S. G.: Pre- and post-flood retention efficiency of nitrogen in a Sonoran desert stream, J. N. Am. Benthol. Soc., 16, 805-819, 1997.

Martí, E., Aumatell, J., Gode, L., Poch, M., and Sabater, F.: Nutrient retention efficiency in streams receiving inputs from wastewater treatment plants, J. Environ. Qual., 33, 285-293, 2004.

Meyer, J. L. and Likens, G. E.: Transport and transformation of phosphorus in a forest stream ecosystem, Ecology, 60, 12551269, 1979.

Mulholland, P. J., Helton, A. M., Poole, G. C., Hall, R. O., Hamilton, S. K., Peterson, B. J., Tank, J. L., Ashkenas, L. R., Cooper, L. W., Dahm, C. N., Dodds, W. K., Findlay, S. E., Gregory, S. V., Grimm, N. B., Johnson, S. L., Mcdowell, W. H., Meyer, J. L., Valett, H. M., Webster, J. R., Arango, C. P., Beaulieu, J. J., Bernot, M. J., Burgin, A. J., Crenshaw, C. L., Johnson, L. T., Niederlehner, B. R., O’Brien, J. M., Potter, J. D., Sheibley, R. W., Sobota, D. J., and Thomas, S. M.: Stream denitrification across biomes and its response to anthropogenic nitrate loading, Nature, 452, 202-205, 2008.

Niyogi, D. K., Bandeff, J. M., Selman, C., and Menke, D. E.: Nutrient flux, uptake, and transformation in a spring-fed stream in the Missouri Ozarks, USA, Aquat. Sci., 72, 203-212, 2010.

Newbold, J. D., Elwood, J. W., O'Neill, R. V., and Van Winkle, W.: Measuring nutrient spiralling in streams, Can. J. Fish. Aquat. Sci., 38, 860-863, 1981

Payn, R. A., Gooseff, M. N., McGlynn, B. L., Bencala, K. B., and Wondzell, S. M.: Channel water balance and exchange with subsurface flow along a mountain headwater stream in Montana, United States, Water Resour. Res., 45, W11427, doi:10.1029/2008WR007644, 2009.

Peterson, B. J., Wollheim, W. M., Mulholland, P. J., Webster, J. R., Meyer, J. L., Tank, J. L., Martí, E., Bowden, W. D., Valett, H. M., Hershey, A. E., McDowell, W. H., Dodds, K. D., Hamilton, S. K., Gregory, S. V., and Morrall, D.: Control of nitrogen export from watersheds by headwater streams, Science, 292, 86-90, 2001. 
Roberts, B. J. and Mulholand, P. J.: In-stream biotic control of nutrient biogeochemistry in a forested stream, West Fork of Walker Branch, J. Geophys. Res., 112, G04002, doi:10.1029/2007JG000422, 2007.

Webster, J. R. and Valett, H. M.: Solute dynamics, in: Methods in stream ecology, edited by: Hauer, F. R. and Lamberti, G. A., Academic Press, San Diego, CA, USA, 169-185, 2006.

von Schiller, D., Martí, E., Riera, J. L., Ribot, M., Argerich, A., Fonollà, P., and Sabater, F.: Inter-annual, annual and seasonal variation of $\mathrm{P}$ and $\mathrm{N}$ retention in a perennial and an intermittent stream, Ecosystems, 11, 670-687, 2008.
Wollheim, W. M., Vorosmarty, C. J., Bouwman, A. F., Green, P., Harrison, J., Linder, E., Peterson, B. J., Seitzinger, S. P., and Syvitski, J. P. M.: Global N removal by freshwater aquatic systems using a spatially distributed, within-basin approach, Global Biogeochem. Cy., 22, GB2026, doi:10.1029/2007GB002963, 2008. 